\title{
Gambaran fungsi kognitif pada lansia di Desa Koka Kecamatan Tombulu
}

\author{
${ }^{1}$ Chandra H. Manurung \\ ${ }^{2}$ Winifred Karema \\ ${ }^{2}$ Junita Maja P. S.
}

\author{
${ }^{1}$ Kandidat Skripsi Fakultas Kedokteran Universitas Sam Ratulangi Manado \\ ${ }^{2}$ Bagian Neurologi Fakultas Kedokteran Universitas Sam Ratulangi Manado \\ Email: candramanurung@yahoo.co.id
}

\begin{abstract}
Impairment of cognitive function is the most cause of dependency in elderly. This occurs due to aging that causes anatomical changes such as waning of the brain and biochemical changes in the central nervous system. The purpose of this study was to determine the cognitive function in elderly people at Koka village, Tombulu district. This was a descriptive cross sectional study from primary mental health data. There were 53 respondents who were eligible to the inclusion criteria. This study showed the result of MMSE, $77.4 \%$ with a normal cognitive function, $20.8 \%$ with a probable cognitive disruption, and $1.8 \%$ with a definite cognitive disruption. This study showed from Mini Cog test, $64.2 \%$ with a normal cognitive function $28.3 \%$ with a probable cognitive disruption and $7.5 \%$ with a definite cognitive disruption. Conclusion: Based on the result, it can be concluded that most of the elderly people at Koka village, Tombulu district have a normal cognitive function
\end{abstract}

Keywords: cognitive function, elderly people, MMSE, mini cog

\begin{abstract}
Abstrak: Dikalangan lansia, penurunan fungsi kognitif merupakan penyebab terbesar terjadinya ketergantungan terhadap orang lain untuk merawat diri sendiri. Hal ini disebabkan karena dengan semakin meningkatnya umur mengakibatkan perubahan-perubahan anatomi, seperti menyusutnya otak dan perubahan biokimiawi di Sistem Saraf Pusat (SSP). Tujuan dari penelitian ini adalah untuk mengetahui gambaran fungsi kognitif pada lansia di Desa Koka Kecamatan Tombulu. Bentuk peneltian ini adalah deskriptif, dengan menggunakan metode cross sectional dari data primer hasil pemeriksaan status mental. Sampel dalam penelitian ini berjumlah 53 orang yang sesuai kriteria inklusi dan bersedia menjadi responden. Hasil penelitian didapatkan bahwa dengan pemeriksaan MMSE $77.4 \%$ yang memiliki fungsi kognitif normal berjumlah, $20.8 \%$ dengan probable gangguan kognitif , dan $1.8 \%$ dengan definite gangguan kognitif, lalu hasil dengan pemeriksaan Mini Cog didapatkan $64.2 \%$ yang memiliki fungsi kognitif normal, $28.3 \%$ dengan probable gangguan kognitif dan 7.5\% dengan definite gangguan kognitif. Simpulan: Dari hasil penelitian didapatkan bahwa sebagian besar lansia di Desa Koka Kecamatan Tombulu memiliki gambaran fungsi kognitif yang normal.
\end{abstract}

Kata kunci: fungsi kognitif, lansia, MMSE, mini cog

Menurut data dari Perserikatan BangsaBangsa (PBB), saat ini Indonesia mengalami jumlah peningkatan warga berusia lanjut yang tertinggi di dunia karena hanya dalam kurun waktu 35 tahun
(1990-2025) jumlah peningkatan warga berusia lanjut mencapai 414 persen. Dari data yang diperoleh lembaga demografi Universitas Indonesia, presentasi jumlah penduduk usia lanjut tahun 1985 adalah 3,5 
persen dari total penduduk, pada tahun 1990 meningkat menjadi 5,8 persen, tahun 2000 meningkat lagi mencapai 7,4 persen dan bahkan pada tahun 2010 mencapai 8,0 persen dari jumlah penduduk. ${ }^{1}$ Dari hasil sensus terbaru tahun 2014 presentasi jumlah penduduk usia lanjut meningkat lagi mencapai $8,03 \%$ dari seluruh penduduk Indonesia atau setara 20,24 juta jiwa. ${ }^{2}$

Dengan meningkatnya populasi lanjut usia maka akan meningkatkan masalah baru diberbagai bidang. Dalam bidang kesehatan, masalah baru yang seringkali dihadapi ialah berhubungan dengan cara untuk selalu mempertahankan kesehatan dari para lansia sehingga para lansia mampu untuk melanjutkan fungsi kehidupan seperti: mampu beraktifitas fisik, serta mempertahankan fungsi sosial dan fungsi kognitif. ${ }^{3}$

Kognitif adalah salah satu fungsi tingkat tinggi otak manusia yang terdiri dari beberapa aspek seperti; persepsi visual dan konstruksi kemampuan berhitung, persepsi dan pengguanan bahasa, pemahaman dan penggunaan bahasa, proses informasi, memori, fungsi eksekutif, dan pemecahan masalah sehingga jika terjadi gangguan fungsi kognitif dalam jangka waktu yang panjang dan tidak dilakukan penanganan yang optimal dapat mengganggu aktifitas sehari-hari. ${ }^{4}$

Di kalangan lansia sendiri penurunan fungsi kognitif merupakan penyebab terbesar terjadinya ketergantungan terhadap orang lain untuk merawat diri sendiri akibat ketidakmampuan dalam melakukan aktifitas sehari-hari. ${ }^{5}$ Hal ini disebabkan karena dengan semakin meningkatnya umur mengakibatkan perubahan-perubahan anatomi, seperti menyusutnya otak dan perubahan biokimiawi di Sistem Saraf Pusat (SSP) sehingga dengan sendirinya dapat menyebabkan penurunan fungsi kognitif. ${ }^{6}$ Dari beberapa penelitian yang dilakukan untuk menilai fungsi kognitif pada lansia ditemukan hasil bahwa pada sebagian besar lansia mulai mengalami penurunan gangguan kognitif dan bahkan beberapa lansia sudah mengalami gangguan kognitif. ${ }^{7}$
Penelitian ini bertujuan untuk mengetahui gambaran fungsi kognitif pada lansia di desa Koka Kecamatan Tombulu.

\section{METODE PENELITIAN}

Jenis penelitian yang digunakan yaitu deskriptif dengan desain potong lintang. Penelitian dilakukan sejak bulan Oktober hingga November 2016, yang bertempat di Desa Koka Kecamatan Tombulu. Populasi penelitian ialah seluruh lansia yang berdomisili di Desa Koka Kecamatan Tombulu sera terdaftar sebagai warga Desa, sedangkan sampel penelitian ialah lansia yang memenuhi kriteria inklusi.

Kriteria inklusi ialah berusia di atas 60 tahun, bisa baca tulis (tidak buta huruf), dalam keadaan umum yang baik, dan bersedia mengikuti penelitian ini. Instrumen yang digunakan untuk mengetahui fungsi kognitif ialah dengan pemeriksaan MMSE (Mini Mentas State Examination) dan Mini Cog.

\section{HASIL PENELITIAN}

Pada penelitian ini didapatkan hasil 53 sampel. Tabel 1 menunjukan bahwa jenis kelamin terbanyak adalah perempuan $(60,4 \%)$.

Tabel 1. Distribusi berdasarkan jenis kelamin

\begin{tabular}{ccc}
\hline Jenis kelamin & $\mathbf{N}$ & $\mathbf{\%}$ \\
\hline Laki-Laki & 21 & 39,6 \\
Perempuan & 32 & 60,4 \\
Total & 53 & 100,0 \\
\hline
\end{tabular}

Tabel 2 menunjukan bahwa usia terbanyak ialah kelompok usia 60-74 tahun (58,5\%). Tabel 3 menunjukan bahwa sampel terbanyak berada di tingkat pendidikan Sekolah Dasar (50,9\%). Tabel 4 menunjukan bahwa responden terbanyak memiliki pekerjaan sebagai petani $(53 \%)$

Tabel 2. Distribusi berdasarkan usia

\begin{tabular}{ccc}
\hline Usia & $\mathbf{N}$ & $\%$ \\
\hline $60-74$ & 31 & 58,5 \\
$75-89$ & 22 & 41,5 \\
Total & 53 & 100,0 \\
\hline
\end{tabular}


Tabel 3. Distribusi berdasarkan tingkat pendidikan

\begin{tabular}{ccc}
\hline Pendidikan & $\mathbf{N}$ & $\mathbf{\%}$ \\
\hline SD & 27 & 50,9 \\
SMP & 13 & 24,5 \\
SMA & 12 & 22,7 \\
Perguruan Tinggi & 1 & 1,9 \\
Total & 53 & 100,0 \\
\hline
\end{tabular}

Tabel 4. Distribusi berdasarkan pekerjaan

\begin{tabular}{ccc}
\hline Pekerjaan & N & \% \\
\hline Petani & 28 & 53 \\
PNS & 7 & 13,2 \\
TNI/Polri & 5 & 9,4 \\
Wiraswasta & 2 & 3,8 \\
Ibu rumah tangga & 11 & 20,6 \\
Total & 53 & 100,0 \\
\hline
\end{tabular}

Tabel 5 menunjukan hasil pemeriksaan MMSE sebagian besar responden normal $(77,4 \%)$

Tabel 5. Distribusi fungsi kognitif menurut skor MMSE

\begin{tabular}{ccc}
\hline MMSE & N & \% \\
\hline Normal & 41 & 77,4 \\
Probable gangguan kognitif & 11 & 20,8 \\
Definite gangguan kognitif & 1 & 1,8 \\
Total & 53 & 100,0 \\
\hline
\end{tabular}

Tabel 6 menunjukan hasil pemeriksaan Mini Cog sebagian besar responden normal $(64,2 \%)$

Tabel 6. Distribusi fungsi kogntif menurut pemeriksaan Mini Cog

\begin{tabular}{ccc}
\hline Mini Cog & N & \% \\
\hline Normal & 34 & 64,2 \\
Probable gangguan kognitif & 15 & 28,3 \\
Definite gangguan kognitif & 4 & 7,5 \\
Total & 53 & 100,0 \\
\hline
\end{tabular}

\section{BAHASAN}

Dalam penelitian ini ditetapkan kelompok yang mengalami gangguan penurunan fungsi kognitif baik dengan menggunakan pemeriksaan MMSE dan Mini Cog ialah yang masuk ke dalam kriteria probable dan definite gangguan kognitif, sedangkan yang mendapatkan hasil pemeriksaan normal masuk ke dalam dalam kriteria tidak terganggu.

Berdasarkan jenis kelamin terlihat bahwa dengan pemeriksaan MMSE dan Mini Cog laki-laki (28,6\%) lebih menunjukan penurunan fungsi kognitif dibandingkan perempuan. Hal ini berbeda dengan penelitian fungsi kognitif lainnya yang mengatakan wanita lebih cenderung mengalami penurunan fungsi kognitif dibandingkan laki-laki. ${ }^{8}$ Perbedaan ini mungkin disebabkan karena dalam penelitian ini peneliti tidak melihat apakah subyek menderita penyakit-penyakit seperti: hipertensi, stroke, diabetes melitus yang menurut penelitian menunjukkan adanya hubungan yang jelas dengan penuruan fungsi kognitif. ${ }^{5}$ Penelitian yang dilakukan oleh Ulfa ${ }^{9}$ melaporkan bahwa jenis kelamin tidak berpengaruh terhadap penurunan fungsi kongnitif.

Pada pemeriksaan MMSE dan Mini Cog berdasarkan kelompok usia terlihat penurunan fungsi kognitif terbanyak pada golongan usia 75-89 tahun (50\%) dengan pemeriksaan Mini Cog dan $(27,3 \%)$ dengan pemeriksaan MMSE dibandingkan usia 60-74 tahun. Hasil ini sesuai dengan kepustakaan yang mengatakan bahwa meningkatnya usia mengakibatkan perubahaan anatomi, seperti menyusutnya otak dan perubahan neurostransmiter yang mengakibatkan terjadinya penurunan fungsi kognitif. ${ }^{1}$ Hal ini juga sejalan dengan penelitian yang dilakukan oleh Kalaria et al. ${ }^{8}$ yang mengatakan bahwa faktor risiko yang paling konsisten menyebabkan penurunan fungsi kognitif dari penelitianpenelitian yang ada di seluruh dunia ialah usia. $^{2}$

Berdasarkan tingkat pendidikan didapatkan bahwa tingkat pendidikan terbanyak yang menunjukan penurunan fungsi kognitif tertinggi ialah sekolah dasar $(33,3 \%)$ dibandingkan tingkat pendidikan yang lebih tinggi. Hal ini sangat sejalan dengan penelitian yang dilakukan oleh Ardila el al. ${ }^{10}$ yang mengatakan bahwa pendidikan merupakan salah satu faktor penting dalam mencegah terjadinya penurunan fungsi kogntif.

Pemeriksaan fungsi kognitif berdasar- 
kan jenis perkerjaan terlihat bahwa pekerjaan tersering yang mengalami penurunan fungsi kogntif ialah petani (40,8\%), diikuti oleh ibu rumah tangga, sedangkan untuk pekerjaan PNS dan TNI/POLRI tidak mengalami penurunan fungsi kognitif dengan pemeriksaan MMSE. Penelitian yang dilakukan oleh Smyth $\mathrm{K}$ et al. mengatakan bahwa pekerjaan yang menekankan kemampuan berpikir memiliki peranan yang besar terhadap neuropatologi gangguan kognitif dibandingkan dengan pekerjaan yang menekankan kekuatan otot seperti petani. ${ }^{5}$

\section{SIMPULAN}

Dari hasil penelitian dan bahasan dapat disimpulkan bahwa sebagian besar lansia memiliki fungsi kognitif dalam batas normal dengan pemeriksaan MMSE dan Mini Cog. Kelompok lansia yang paling menunjukan penurunan fungi kognitif ialah usia 74-89 tahun, jenis kelamin laki-laki, riwayat pendidikan terakhir lulusan SD, dan riwayat pekerjaan sebagai petani.

\section{SARAN}

Pentingnya dilakukan skrining atau pemeriksaan fungsi kognitif pada lansia di desa agar dapat dilakukan pencegahan bila terdapat penurunan fungsi kognitif.

Pentingnya dilakukan kegiatan kebersamaan di desa dengan melibatkan para lansia seperti senam pagi, ibadah, lomba, dll agar dapat terus merangsang fungsi kognitif lansia

Pentingnya dilakukan penyuluhan fungsi kognitif agar masyarakat lebih mengetahui dan mengenal faktor-faktor pencetus penurunan fungsi kognitif

Pentingnya dilakukan peningkatan pendidikan sehingga menurunkan salah satu faktor resiko penyebab penurunan fungsi kognitif yaitu pendidikan.

\section{DAFTAR PUSTAKA}

1. Soejono CH. Pengkajian paripurna pada pasien geriatric. dalam: Setiati S, Alwi I, Sudoyo AW, Simadibrata KM, Setiyohadi B, Syam AF, pengarang. Buku ajar ilmu penyakit dalam. edisi 6 .
Jakarta: Internapublishing; 2014. h. 3705-13.

2. Darmojo RB. Demografi dan epidemologi populasi usia lanjut. dalam: Martono $\mathrm{HH}$, Pranarka K, pengarang. Buku ajar boedhi-darmojo geratri. edisi ke-4. Jakarta: Balai penerbit fakultas kedokteran universitas indonesia; 2011. h. 35-55.

3. Nevriana A, Riono P, Rihardjo T, Kusumadjati A. Lifetime musical activities and cognitive function of the elderly. Universitas Indoneisa; 2012.

4. Wibowo MM, Karema W, Sampoerna JMP. Gambaran fungsi kognitif dengan INA-MoCA dan MMSE pada penderita post stroke di Poliklinik Saraf BLU RSUP Kandou Manado November - Desember 2014. Jurnal eclinic. 2015;3:754-7.

5. Mongisidi R. Profil penurunan fungsi kognitif pada lansia di Yayasan-yayasan Manula di Kecamatan Kawangkoan. [Skripsi]. [Manado(ID)]. Universitas Samratulagi; 2013.

6. Darmojo RB. Teori proses menua. dalam: Martono HH, Pranarka K, pengarang. Buku ajar boedhi-darmojo geratri. edisi ke-4. Jakarta: Balai penerbit fakultas kedokteran universitas indonesia; 2011. hal. 3-12.

7. Sundariyati IGAH, Ratep N, Westa W. Gambaran faktor-faktor yang mempengaruhi status kognitif pada lansia di wilayah kerja Puskesmas Kubu II, Januari-Februari 2014. ejurnal medika udayana. 2015;4:1-12.

8. Kalaria N, Maestre E, Arizaga R, Friedland R.P, Galasko D, Hall $\mathbf{K}$, et all. Alzheimer's disease and vascular dementia in developing countries: prevalence, management, and risk factors. Lancet neurology 2008; 7: 81226

9. Ulfa Z. Faktor-Faktor yang Mempengaruhi Fungsi Kognitif Usia Lanjut di UPTD Seujahtera Geunaseh Sayang Banda Aceh. Banda Aceh : Universitas Syiah Kuala, 2015.

10. Ardila A, Feggy F, Roselli M. Age-related Cognitive Decline During Normal Aging: The Complex Effect of Education. 2000. Arch Clin Neuropsychol. 2000;15(6):495-513 